\title{
Bronchial vascular remodelling in patients with COPD and its relationship with inhaled steroid treatment
}

\author{
A Zanini, ${ }^{1}$ A Chetta, ${ }^{2}$ M Saetta, ${ }^{3}$ S Baraldo, ${ }^{3}$ C Castagnetti, ${ }^{2}$ G Nicolini, ${ }^{2}$ M Neri, ${ }^{1}$ \\ D Olivieri ${ }^{2}$
}

${ }^{1}$ Salvatore Maugeri Foundation, Division of Pneumology, IRCCS Rehabilitation Institute of Tradate, Italy; ${ }^{2}$ Department of Clinical Sciences, Section of Respiratory Diseases, University of Parma, Italy: ${ }^{3}$ Department of Cardiac, Thoracic and Vascular Sciences, Section of Respiratory Diseases, University of Padua, Italy

Correspondence to: Dr A Zanini, Divisione di Pneumologia, Fondazione Salvatore Maugeri, IRCCS, Via Roncaccio, 16-21049 Tradate, Italia; azanini@fsm.it

Received 31 January 2009 Accepted 22 August 2009 Published Online First

6 September 2009

\section{ABSTRACT}

Background: Only a few studies have evaluated microvascular changes and proangiogenetic mediators in the bronchial mucosa of patients with chronic obstructive pulmonary disease (COPD), and the results have been discordant. Furthermore, the role of inhaled corticosteroids (ICS) in COPD has not been extensively studied. A study was undertaken to evaluate vascular remodelling, its relationship with inflammatory cells and treatment effects in the bronchial mucosa of patients with COPD. Methods: The study comprised three groups: (1) 10 nontreated patients with COPD (COPD); (2) 10 patients with COPD treated with nebulised beclomethasone dipropionate $1600-2400 \mu \mathrm{g}$ daily (equivalent to $800-1200 \mu \mathrm{g}$ via metered dose inhaler) (COPD/ICS); and (3) 8 control subjects (CS). Bronchial biopsies were evaluated for number and size of vessels and vascular area. Specimens were also examined for vascular endothelial growth factor (VEGF), basic fibroblast growth factor (bFGF) and transforming growth factor $\beta$ (TGF- $\beta$ ) expression and inflammatory cell counts were performed.

Results: Vascular area, vessel size, VEGF+ cells, bFGF+ cells and TGF- $\beta+$ cells were significantly increased in the COPD group compared with the COPD/ICS and CS groups (all $p<0.05$ ). In addition, bFGF+ cells were significantly increased in the COPD/ICS group compared with the CS group, and CD8+ and CD68+ cells were significantly increased in the COPD group compared with the COPD/ ICS and CS groups $(p<0.05)$. In the COPD group the VEGF+ cells correlated with the number of vessels $(p<0.05)$, vascular area $(p<0.01)$ and vessel size $(p<0.05)$, and TGF- $\beta+$ cells correlated significantly with vascular area $(p<0.05)$.

Conclusion: Bronchial vascular remodelling in patients with COPD is mainly related to morphological changes of the mucosal microvessels rather than to new vessel formation, and may be reduced in patients treated with steroids.

Most of the literature regarding bronchial angiogenesis in chronic airway inflammation results from studies in patients with asthma ${ }^{1}$ since the vascular component of airway remodelling significantly contributes to changes in the airway wall in asthma. $^{23}$ The bronchial microvasculature may alter the bronchial wall by increasing vessel calibre, oedema formation and by increasing the number of vessels. $^{45}$

It has been suggested that bronchial vascular changes may also occur in chronic obstructive pulmonary disease (COPD), although this phenomenon seems to be less evident than in asthma. ${ }^{6}$ There is no agreement on the presence of angiogenesis in the bronchial mucosa of patients with COPD, but an increase in the vascular area appears to be a common feature in these patients. ${ }^{78}$ Nevertheless, microvascular changes may contribute to increased airway wall thickness and may therefore be associated with the progression of COPD.

The pathological mechanisms of bronchial vascular remodelling have not been clearly elucidated, even though recent investigations have emphasised the role of growth factors and cytokines. The expression of vascular endothelial growth factor (VEGF), basic fibroblast growth factor (bFGF) and transforming growth factor $\beta$ (TGF- $\beta$ ) is higher in the airways of patients with COPD than in healthy subjects, and is related to the bronchial vascularity. ${ }^{10-12}$ In particular, VEGF, the most potent mediator of angiogenesis, can play a significant role in the pathophysiology of two major phenotypes of COPD-chronic bronchitis and emphysema. ${ }^{13}$ VEGF levels are significantly higher in patients with chronic bronchitis compared with controls, but are significantly reduced in patients with emphysema. ${ }^{14}$ In addition, the bronchial epithelial expression of VEGF, FGF-1, FGF-2 and FGF receptor-1 (FGFR-1) is negatively correlated with lung function and positively correlated with the smoking history. ${ }^{10} 11$

To date there have been few published data regarding the relationship between bronchial microvascularity and airway inflammation and remodelling in COPD, even though inflammatory changes in the airways are central to the pathogenesis of COPD. ${ }^{15}{ }^{16}$ In patients with COPD there is evidence that VEGF and its receptors Flt-1 and KDR/Flk-1 can be involved in peripheral vascular and airway remodelling processes and, accordingly, in the development of airway obstruction. ${ }^{10}$ Moreover, although there is evidence that inhaled corticosteroids (ICS) can be clinically effective in patients with severe COPD, ${ }^{17}$ only a few studies ${ }^{18-20}$ have been conducted to assess the effect of ICS on airway inflammation and remodelling in COPD. In particular, no study has evaluated the effect of ICS on the vascular component of airway remodelling in COPD.

In this study we hypothesised that the vascular component of airway remodelling in patients with COPD is associated with airway inflammation and investigated whether it was related to the use of anti-inflammatory treatment. The aims of this cross-sectional study were therefore to quantify the bronchial microvascular changes in endobronchial biopsies of patients with COPD in comparison with control subjects, to examine the relationship between vascularity, angiogenic factors and 
inflammatory cells, and to evaluate whether the bronchial vascularity in patients with COPD is related to the use of ICS.

\section{METHODS}

\section{Subjects}

The study included patients with COPD who were clinically stable and did not require long-term oxygen therapy. Twenty patients were recruited from the Section of Respiratory Diseases of the Department of Clinical Sciences of the Parma University. The patients were all ex-smokers of at least 10 years with stable moderate to severe COPD, according to the Global Initiative for Chronic Obstructive Lung Disease (GOLD) classification. ${ }^{21}$ They were divided into two groups: those not receiving treatment with ICS (COPD, $n=10)$ and those being treated with ICS $(\mathrm{COPD} / \mathrm{ICS}, \mathrm{n}=10)$. The COPD/ICS group had experienced more exacerbations in the previous year than the COPD group. Patients in the COPD/ICS group were treated with nebulised beclomethasone dipropionate (BDP) at a daily dose of 1.6$2.4 \mathrm{mg}$ (equivalent to $800-1200 \mu \mathrm{g}$ via metered dose inhaler), ${ }^{22}$ administered for at least 2 months. At the time of the study all reliever medications, inhaled $\beta_{2}$ agonists, anticholinergic agents and theophylline were continued as previously administered and required. Six of the patients in the COPD group and eight in the COPD/ICS group were receiving treatment with an inhaled long-acting bronchodilator (formoterol, salmeterol or tiotropium) and inhaled salbutamol as needed; the remaining four patients in the COPD group and two patients in the COPD/ICS group were being treated with oral sustained-release theophylline and inhaled salbutamol as needed. All patients were free from exacerbations in the previous 2 months and were nonatopic. Age-matched, non-atopic, lifelong non-smoking volunteers were enrolled as a control group. The control subjects underwent fibreoptic bronchoscopy for diagnostic reasons (six subjects for cryptogenic haemoptysis and two for a solitary peripheral nodule). All study subjects denied any clinical history of allergic disease.

\section{Study design}

This was a cross-sectional study. On two different study days, the subjects in the three study groups (COPD, COPD/ICS and control subjects) underwent clinical and functional evaluation as well as fibreoptic bronchoscopy. The subjects included in the three groups were recruited, sampled and analysed concurrently.

\section{Fibreoptic bronchoscopy}

Fibreoptic bronchoscopy was performed according to a previously described protocol.$^{23}$ Premedication consisted of atropine (0.5 $\mathrm{mg})$ and diazepam $(10 \mathrm{mg})$, both given by intramuscular injection. Local anaesthesia was obtained with a tetracaine tablet (20 mg) given $15 \mathrm{~min}$ before bronchoscopy. An additional aliquot of $2 \%$ lidocaine was aerosolised into the upper airways and applied topically to the pyriform sinuses and vocal cords to prevent coughing and as a local anaesthetic. Nebulised salbutamol $(1.25 \mathrm{mg})$ and ipratropium bromide $(0.25 \mathrm{mg})$ were administered $5 \mathrm{~min}$ before bronchoscopy (Model 1T10; Olympus, Tokyo, Japan). Three to five mucosal biopsy specimens were taken at the subcarinae in the middle and lower lobes of the right lung. Administration of nebulised salbutamol and ipratropium bromide was repeated after bronchoscopy when necessary. Patients were closely monitored after bronchoscopy in the outpatient clinic and were discharged when the effects of sedation had disappeared and lung function had returned to baseline values.

\section{Biopsy processing}

Mucosal biopsies were immediately transferred into ice-cold acetone containing the protease inhibitor iodoacetamide $(20 \mathrm{mM})$ and phenylmethylsulfonylfluoride $(2 \mathrm{mM})$ for fixation; they were then stored at $-20^{\circ} \mathrm{C}$ for $24 \mathrm{~h}$ and processed into the water-soluble resin glycolmethacrylate (Polysciences, Northampton, UK) for embedding. ${ }^{24}$ Biopsies were considered suitable for examination when there was at least $2.0 \mathrm{~mm}$ of basement membrane length and $0.2 \mathrm{~mm}^{2}$ of subepithelial area.

Sections of $2 \mu \mathrm{m}$ were cut and incubated with primary antibodies for $16-20 \mathrm{~h}$ overnight at room temperature. Monoclonal antibodies directed against the following markers were used: endothelial basement membrane (collagen IV, 1:400, Novocastra Laboratories, Newcastle, UK), VEGF (121, 165 and 189 isoforms of VEGF, 1:50, NeoMarkers, Fremont, California, USA), bFGF (1:25, BD Biosciences Pharmingen, San Jose, California, USA), TGF- $\beta$ (1:25, Novocastra Laboratories), lymphocytes (CD3, CD4, CD8, 1:50, Dako, Glostrup, Denmark), macrophages (CD68, 1:50, Dako), neutrophils (anti-elastase, 1:50, Dako), mast cells (tryptase, 1:200, Dako) and eosinophils (1:1000, Pharmacia and Upjohn Diagnostics AB, Uppsala, Sweden). After washing in Tris-buffered saline (TBS), the sections were incubated for $2 \mathrm{~h}$ with biotin-conjugated secondary antibody (Vector Lab, Burlingame, California, USA). Light microscopy was performed with a Leica microscope (Leica DMLB, Werzlar, Germany) at $1000 \times$ magnification.

As previously described, ${ }^{25}$ the vascularity and number of cells, including both inflammatory cells and cells positive for VEGF, bFGF and TGF $\beta$, were quantified in all non-overlapping high power fields in the subepithelial lamina propria, defined as a zone $100 \mu \mathrm{m}$ below the epithelial basement membrane, and expressed as the number of vessels and cells per square millimetre of lamina propria. In each section, all available non-overlapping high power fields with intact tissue covered by intact basement membrane were examined. The vascular area was expressed as a percentage of the area of the assessed lamina propria. The mean size of the vessels was estimated by dividing the total vascular area by the total number of vessels. Final values represent the mean of at least two sections from two different biopsy specimens in each subject. A single observer (AZ) who had no knowledge of the patient characteristics evaluated the tissue sections using an image analysis system (Image-Pro Plus; MediaCybernetics, Silver Spring, Maryland, USA). An average of eight power fields were examined for each subject included in the study. The mean coefficient of variation for repeated measurements ranged from $6 \%$ to $11 \%$ for the inflammatory cells and the growth factor-positive cells, and from $4 \%$ to $7 \%$ for vascular data.

\section{Statistical analysis}

Values are presented as mean (standard deviation, SD) or median (interquartile range, IOR). Differences between the groups were analysed by a non-parametric Kruskal-Wallis ANOVA test followed, where significant, by the MannWhitney $U$ test for comparisons between groups. Relationships were estimated by the Spearman rank correlation coefficient $\left(\mathrm{r}_{\mathrm{s}}\right)$. A $\mathrm{p}$ value of $\leqslant 0.05$ was taken as significant. Intra-observer variation was determined by counting the mean coefficient of variation for repeated measurements. 
Table 1 Characteristics of patients with chronic obstructive pulmonary disease (COPD) and control subjects

\begin{tabular}{|c|c|c|c|c|c|}
\hline & $\begin{array}{l}\text { COPD } \\
(n=10)\end{array}$ & $\begin{array}{l}\text { COPD/ICS } \\
(\mathrm{n}=10)\end{array}$ & $\begin{array}{l}\text { Control subjects } \\
(n=8)\end{array}$ & p Value* & p Value $\dagger$ \\
\hline Age (years) & 77 (8) & $75(11)$ & 66 (17) & 0.236 & 0.360 \\
\hline Sex (F/M) & $0 / 10$ & $3 / 7$ & $5 / 3$ & & \\
\hline $\mathrm{FEV}_{1}$ (\% predicted) & $51(16)$ & $50(14)$ & $104(22)$ & 0.001 & 0.001 \\
\hline $\mathrm{FEV}_{1} / \mathrm{VC}(\%)$ & $49(10)$ & $48(14)$ & $76(3)$ & 0.001 & 0.001 \\
\hline TLC (\% predicted) & $106(14)$ & $123(27)$ & 119 (17) & 0.203 & 0.408 \\
\hline
\end{tabular}

\section{RESULTS}

The characteristics of the patients with COPD and control subjects are reported in table 1 . In the patients with COPD the lung function values were recorded after bronchodilator administration.

Fibreoptic bronchoscopy with endobronchial biopsy specimens was performed successfully and was well tolerated in all subjects. Data on vascularity, growth factor expression and inflammatory cells are summarised in table 2.

Vascular area and vessel size were significantly increased in the COPD group compared with the COPD/ICS group $(p=0.043)$ and control subjects $(p=0.001)$; no difference was found in vessel number between the three groups (fig 1). VEGF+ cells were significantly increased in the COPD group compared with the COPD/ICS group and control subjects $(p=0.043$ and $p=0.003$, respectively). bFGF + cells and TGF- $\beta+$ cells were significantly increased in the COPD group compared with the COPD/ICS group $(p=0.035$ and $p=0.001$, respectively) and control subjects $(p=0.001)$. In addition, bFGF+ cells were significantly increased in the COPD/ICS group compared with the control subjects $(p=0.001)$.

When cell profiles between the groups were examined, CD8+ cells and CD68+ cells were significantly increased in the COPD group compared with the COPD/ICS group ( $p=0.023$ and $p=0.001$, respectively) and control subjects ( $p=0.007$ and $p=0.001$, respectively), whereas no difference was found in the number of CD3+ cells, CD4+ cells, neutrophils and eosinophils.
In the COPD group the number of mast cells tended to be higher than in healthy subjects $(p=0.055)$.

In the COPD group the number of VEGF+ cells was related to the vascular area $\left(r_{s}=0.82, p<0.01\right.$; figs 2 and 3$)$, the number of vessels $\left(r_{s}=0.75, p<0.05\right)$ and the vessel size $\left(r_{s}=0.68\right.$, $p<0.05)$. Moreover, in the same group of patients the number of TGF- $\beta+$ cells was significantly related to the vascular area $\left(r_{s}=0.66, p<0.05\right.$; figs 2 and 3$)$. In no study group were significant correlations observed between vascularity data and inflammatory cells or lung function data.

\section{DISCUSSION}

In this study we assessed bronchial vascular remodelling in the central airways of patients with COPD and examined its relationship both with angiogenic growth factor expression and inflammatory cells. In addition, we evaluated the association between bronchial microvascularity and long-term treatment with inhaled BDP. We found that, in the airways of patients with untreated COPD, the bronchial vascular area and vessel size were increased compared with those of patients with COPD treated with BDP and control subjects. Moreover, there was a higher bronchial expression of VEGF, bFGF and TGF- $\beta$ in patients with untreated COPD than in patients with COPD treated with BDP and in control subjects. Finally, we have provided the first evidence that, in untreated patients with COPD, the vascular component of airway remodelling is

Table 2 Vascular area, vessel size, number of vessels, VEGF+ cells, FGF+ cells, TGF $\beta+$ cells and inflammatory cells in patients with chronic obstructive pulmonary disease (COPD) and control subjects

\begin{tabular}{|c|c|c|c|c|c|c|}
\hline & COPD & COPD/ICS & Control subjects & p Value* & p Value $\dagger$ & p Value: \\
\hline Vascular area (\%) & $6.2(5-6)$ & $4.0(3-6)$ & $4.0(4-4.1)$ & 0.043 & 0.001 & 0.896 \\
\hline Vessel size $\left(\mu \mathrm{m}^{2}\right)$ & $424(389-490)$ & 323 (294-398) & 305 (284-327) & 0.023 & 0.003 & 0.408 \\
\hline Vessel number $\left(\mathrm{n} / \mathrm{mm}^{2}\right)$ & $140(90-165)$ & $134(109-146)$ & $120(113-128)$ & 0.853 & 0.633 & 0.315 \\
\hline VEGF+ cells $\left(\mathrm{n} / \mathrm{mm}^{2}\right)$ & $142(102-157)$ & $102(79-120)$ & 80 (73-95) & 0.043 & 0.003 & 0.274 \\
\hline FGF+ cells $\left(\mathrm{n} / \mathrm{mm}^{2}\right)$ & $50.2(43-64)$ & $36.4(35-45)$ & $21.5(19-23.8)$ & 0.035 & 0.001 & 0.001 \\
\hline TGF- $\beta+$ cells $\left(\mathrm{n} / \mathrm{mm}^{2}\right)$ & 76.5 (31.2-104) & $21(9-31)$ & $10(9-11.9)$ & 0.014 & 0.001 & 0.146 \\
\hline CD3 $\left(\mathrm{n} / \mathrm{mm}^{2}\right)$ & $17.5(16.3-18)$ & $15.7(14-16)$ & $15.5(15-16.5)$ & 0.089 & 0.055 & 0.696 \\
\hline $\mathrm{CD} 4\left(\mathrm{n} / \mathrm{mm}^{2}\right)$ & $3.6(3-5)$ & $3.3(3-4)$ & $2.7(2-3.2)$ & 0.631 & 0.068 & 0.203 \\
\hline $\mathrm{CD} 8\left(\mathrm{n} / \mathrm{mm}^{2}\right)$ & $12.2(10.6-13)$ & $9.7(8-11)$ & $9.4(9-9.8)$ & 0.023 & 0.007 & 0.897 \\
\hline $\operatorname{CD} 68\left(\mathrm{n} / \mathrm{mm}^{2}\right)$ & $80.6(78-104)$ & $45.7(40-57)$ & $44.7(41-49)$ & 0.001 & 0.001 & 0.633 \\
\hline Neutrophils $\left(\mathrm{n} / \mathrm{mm}^{2}\right.$ ) & $55.5(44-78)$ & $48.5(41-58)$ & $45(43-52.5)$ & 0.481 & 0.237 & 0.828 \\
\hline Mast cells $\left(\mathrm{n} / \mathrm{mm}^{2}\right)$ & $35.7(23.6-43)$ & $23.8(16-31)$ & $22.3(22-25.4)$ & 0.053 & 0.055 & 0.998 \\
\hline Eosinophils $\left(\mathrm{n} / \mathrm{mm}^{2}\right)$ & $47.2(34.2-63)$ & $25.7(13-46)$ & $37.1(30-42.4)$ & 0.123 & 0.146 & 0.460 \\
\hline
\end{tabular}

Data presented as median (interquartile range).

COPD, untreated patients with chronic obstructive pulmonary disease; COPD/ICS, patients with chronic obstructive pulmonary disease treated with inhaled corticosteroids; FGF, fibroblast growth factor; TGF- $\beta$, transforming growth factor $\beta$; VEGF, vascular endothelial growth factor.

${ }^{*}$ COPD vs COPD/ICS.

†COPD vs control subjects.

tCOPD/ICS vs control subjects. 

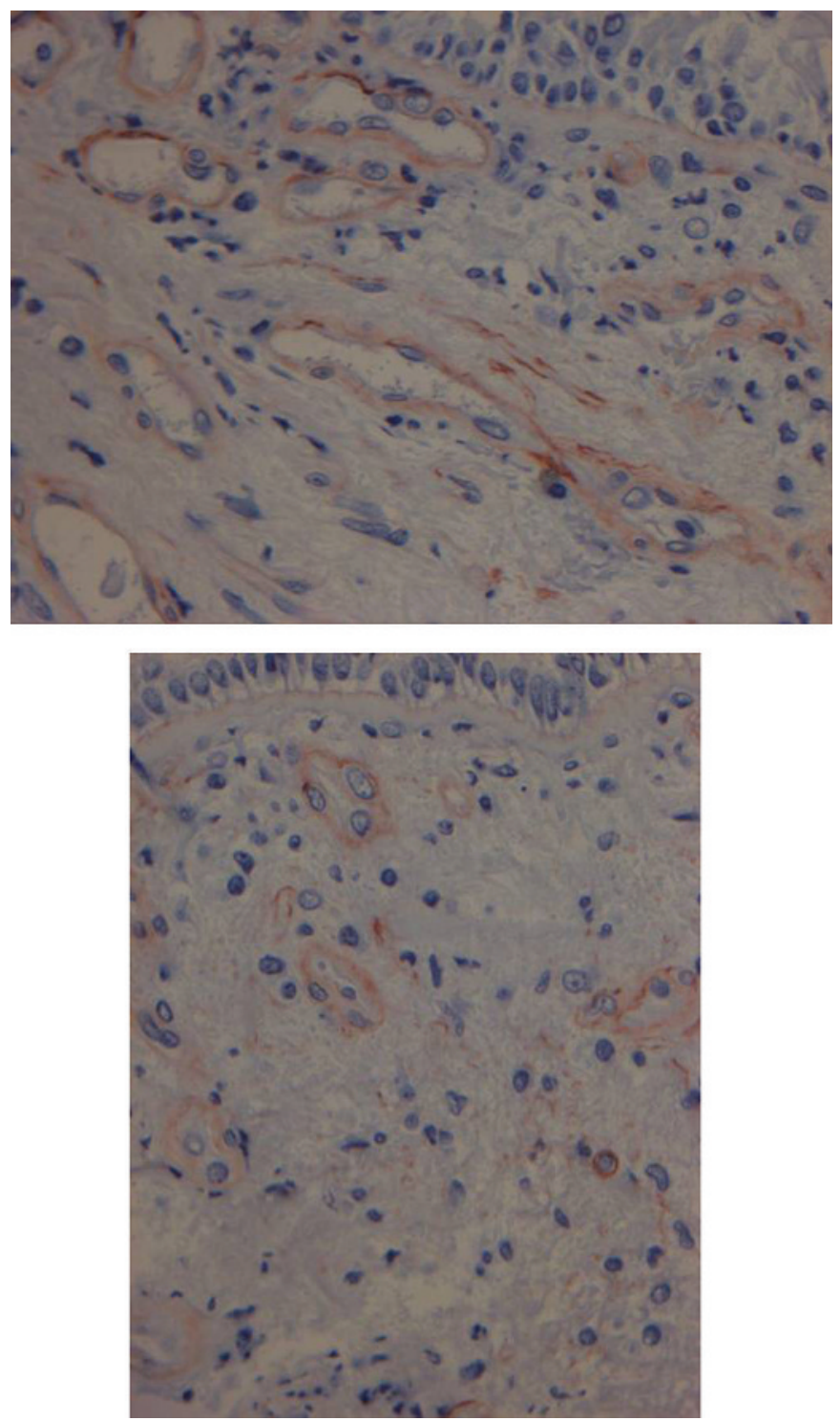

Figure 1 Microphotographs from a patient with untreated chronic obstructive pulmonary disease (COPD, upper panel) and from a patient with COPD treated with inhaled corticosteroids (lower panel) showing bronchial mucosa stained with antibody directed against collagen IV to outline vessels. Original magnification $\times 400$.

positively related to the bronchial expression of VEGF and TGF$\beta$.

Previous studies have reported different findings on the bronchial vascularity in COPD. ${ }^{726}$ Kuwano et a ${ }^{26}$ did not find any increase in bronchial mucosal vascularity in patients with COPD compared with controls. By contrast, more recently Hashimoto et al found that, in patients with COPD not treated with inhaled steroids, the vessel number showed a tendency to increase and the vascular area in the inner zone of the small airways was significantly greater than in control subjects. In addition, Calabrese et $a l^{8}$ found an increase in bronchial vascularity in the central airways of patients with COPD, expressed as both number of vessels and vascular area, compared with controls. Differences in patient selection criteria, vascularity assessment, sampling site or biopsy processing and immunostaining techniques can explain these different results. In particular, Kuwano et a ${ }^{26}$ obtained tissue specimens from lung surgical resections and stained vessels with factor VIII,
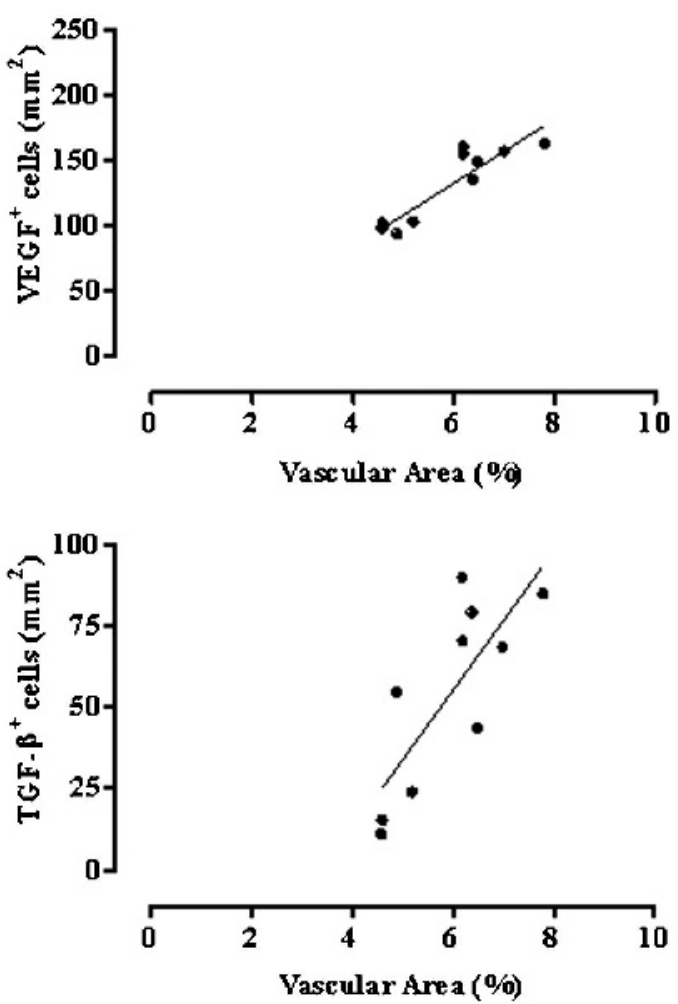

Figure 2 Relationship between the vascular area and the number of vascular endothelial growth factor (VEGF)-positive cells (upper panel, $\left.r_{s}=0.82, p<0.01\right)$ and the number of transforming growth factor $\beta$ (TGF- $\beta$ )-positive cells (lower panel, $r_{s}=0.66, p<0.05$ ) in 10 patients with untreated chronic obstructive pulmonary disease (COPD group).

while Calabrese et al ${ }^{8}$ assessed the bronchial vascular component using fibreoptic bronchoscopy only in patients with COPD who were current smokers. In spite of the differences in methods and patient selection criteria, all the studies consistently found an increased vascular area in the airways of patients with COPD. ${ }^{7} 826$

Among angiogenic growth factors, VEGF is fairly relevant to the angiogenic processes closely related to airway inflammation and remodelling in COPD. ${ }^{13}$ In this study we have confirmed
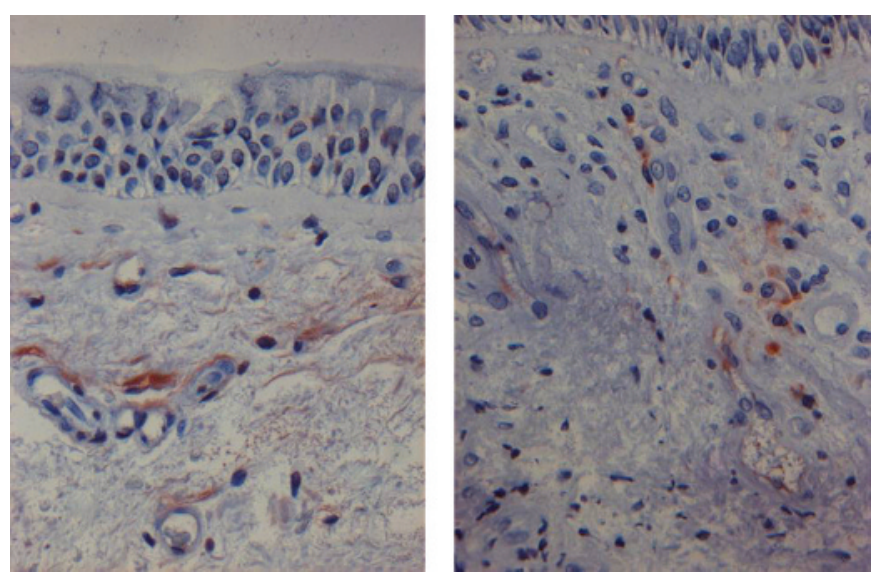

Figure 3 Microphotographs from a patient with untreated chronic obstructive pulmonary disease (COPD group) showing bronchial immunostaining for vascular endothelial growth factor (VEGF, left panel) and transforming growth factor $\beta$ (TGF- $\beta$ right panel). Original magnification $\times 400$. 
that patients with COPD not treated with inhaled steroids may have higher bronchial airway expression of VEGF than healthy non-smoking subjects. It has previously been shown that cellular VEGF expression is increased in the bronchial airways of smoking patients with COPD compared with healthy nonsmokers. ${ }^{8}$ Moreover, Kranenburg et $a l^{10}$ found a higher expression of VEGF in the central and peripheral airways of exsmokers with COPD than in those without COPD. Interestingly, in this study we also found evidence that VEGF expression is directly correlated with the microvascularity of the airway mucosa, both in terms of vessel number and size and of vascular area. Taken together, these findings support the view that VEGF may be one of the main determinants of the vascular changes in the bronchial mucosa of patients with COPD.

In this study we found that bFGF levels were also higher in the airways of patients with COPD than in control subjects. It is of note that bFGF is a growth factor with the potential to contribute to changes in the bronchial microvascularity and pulmonary vessels of patients with COPD. Kranenburg et al ${ }^{1127}$ observed that patients with COPD may have increased expression of FGF-1 in the bronchial epithelium and of FGFR1 in the bronchial epithelium cells, the airway smooth muscle cells and the vascular smooth muscle of the bronchial small vessels compared with subjects without COPD. In addition, it has been found that the expression of FGF-2 is also increased in the central airways of patients where it is correlated with the number of vessels. ${ }^{28}$

The expression of TGF- $\beta$ in the airways of patients with COPD has been assessed by different methods. De Boer et a l. $^{12}$ used a semi-quantitative analysis with a visual analogue scale using in situ hybridisation and immunostaining techniques, while Takizawa et al ${ }^{29}$ used immunocytochemical analysis from cell culture. Both studies reported increased expression of TGF- $\beta$ in patients with COPD compared with controls. We analysed the bronchial mucosal expression of TGF- $\beta$ by immunohistochemistry and, in spite of the difference in methods, our results are in line with those previously reported. ${ }^{12}{ }^{29}$ Furthermore, we found a positive relationship between TGF- $\beta$ and vascular area in patients with COPD without steroid treatment, suggesting a possible role for TGF- $\beta$ in the vascular component of the airway remodelling in COPD. In vitro studies showed that TGF- $\beta$ can act as a regulator in the maintenance of vascular homeostasis. ${ }^{30}$ Moreover, TGF- $\beta$ can increase endothelial nitric oxide synthase (eNOS) and determine NO-dependent vasodilation by binding with endoglin, a component of the TGF- $\beta$ receptor complex. ${ }^{31}$

Although the potential clinical benefits of inhaled steroids in COPD (reduced rate of exacerbations, improvement in quality of life) are well known, ${ }^{32}$ the evidence for their effects on airway inflammation and remodelling in COPD is scarce..$^{19} 193$ Hattotuwa et $a l^{18}$ observed a reduction in the CD8/CD4 ratio in the epithelium and in the numbers of subepithelial mast cells in patients with COPD treated with a high dose of fluticasone propionate. In an ultrastructural biopsy study the same authors also showed a reduction in mast cells in patients with COPD treated with inhaled steroids. ${ }^{19}$ In line with these previous studies, we found that patients with COPD treated with high doses of BDP had lower numbers of CD8+ T lymphocytes and a tendency for mast cells to be lower in the lamina propria compared with untreated patients with COPD. In addition, in agreement with Verhoeven et $a^{133}$ who observed substantial reductions in CD68 cell numbers in the lamina propria of patients with COPD treated with fluticasone propionate, we found that patients with COPD treated with BDP also had fewer CD68+ cells than untreated patients with COPD.
The findings of this study provide the first evidence that patients with COPD not treated with steroids have a greater vascular area and vessel size as well as upregulation of VEGF, FGF and TGF- $\beta$ compared with patients with COPD treated with steroids. Our study suggests that the anti-inflammatory effect of ICS in COPD may also be due, at least in part, to a reduction in vascularity and expression of angiogenic factors in the airways. However, it must be acknowledged that, in a crosssectional study, Paredi et a ${ }^{134}$ have previously shown that, in patients with COPD with mild airway obstruction, bronchial blood flow was not significantly affected by long-term treatment with a low daily dose of budesonide. ${ }^{34}$

There are potential criticisms of our study. We acknowledge that this is a cross-sectional biopsy study which measured large airway vascularity in patients with COPD who were not randomised to treatment. Therefore, we do not infer from our study any causal link between steroid treatment and microvascularity in patients with COPD. However, we performed this study in order to generate a hypothesis, which had to be tested by a properly designed longitudinal study.

Another limitation of our report is the low power of the study because of the small number of subjects in each group. However, a small number of subjects and of biopsies per subject are common limitations in biopsy studies. Moreover, we think that the significant differences we observed are valid, even if we cannot exclude the possibility of type 2 statistical errors (ie, inability to detect small differences). Despite these limitations, we believe that studies on bronchial biopsies provide a unique opportunity to investigate airway inflammation and remodelling in patients with COPD.

To date, the vascular component of airway remodelling in COPD has been remarkably little studied for such an important condition. Our study shows that some aspects of vascular remodelling - such as bronchial vascular area and vessel sizeare increased in the airways of patients with COPD not treated with inhaled steroids, and upregulation of VEGF, bFGF and TGF- $\beta$ could play a key role in these changes. By contrast, angiogenesis does not seem to be a feature of patients with COPD who are not current smokers. Although patients with COPD treated with high doses of nebulised BDP have reduced microvascularity compared with untreated patients, further longitudinal intervention studies are required to assess the effect of inhaled steroids on the vascular component of airway remodelling in COPD.

Acknowledgements: The authors thank Mrs Iris Spanevello for her help in the biopsy processing.

Competing interests: None.

Ethics approval: The study was approved by the University of Parma ethical committee and subjects gave written informed consent to enter the study.

Provenance and peer review: Not commissioned; externally peer reviewed.

\section{REFERENCES}

1. McDonald DM. Angiogenesis and remodeling of airway vasculature in chronic inflammation. Am J Respir Crit Care Med 2001;164:S39-45.

2. Li X, Wilson JW. Increased vascularity of the bronchial mucosa in mild asthma. Am J Respir Crit Care Med 1997;156:229-33.

3. Salvato G. Quantitative and morphological analysis of the vascular bed in bronchial biopsy specimens from asthmatic and non-asthmatic subjects. Thorax 2001; $56: 902-6$

4. Wilson JW, Hii S. The importance of the airway microvasculature in asthma. Curr Opin Allergy Clin Immunol 2006;6:51-5.

5. Chetta A, Zanini A, Torre 0, et al. Vascular remodelling and angiogenesis in asthma: morphological aspects and pharmacological modulation. Inflamm Allergy Drug Targets 2007:1:41-5.

6. Bergeron C, Boulet LP. Structural changes in airway diseases. Chest 2006;129:1068-87. 
7. Hashimoto M, Tanaka H, Abe S. Quantitative analysis of bronchial wall vascularity in the medium and small airways of patients with asthma and COPD. Chest 2005;127:965-72.

8. Calabrese C, Bocchino V, Vatrella A, et al. Evidence of angiogenesis in bronchial biopsies of smokers with and without airway obstruction. Respir Med 2006;100:1415-22

9. Walters EH, Reid D, Soltani A, et al. Angiogenesis: a potentially critical part of remodelling in chronic airway diseases? Pharmacol Ther 2008;118:128-37.

10. Kranenburg AR, de Boer WI, Alagappan VKT, et al. Enhanced bronchial expression of vascular endothelial growth factor and receptors (Flk-1 and Flt-1) in patients with chronic obstructive pulmonary disease. Thorax 2005;60:106-13.

11. Kranenburg AR, Willems-Widyastuti A, Mooi WJ, et al. Chronic obstructive pulmonary disease is associated with enhanced expression of FGF-1, FGF-2 and FGFR-1. J Pathol 2005;206:28-38.

12. de Boer WI, van Schadewijk A, Sont JK, et al. Transforming growth factor beta1 and recruitment of macrophages and mast cells in airways in chronic obstructive pulmonary disease. Am J Respir Crit Care Med 1998;158:1951-7.

13. Kanazawa H. Role of vascular endothelial growth factor in the pathogenesis of chronic obstructive pulmonary disease. Med Sci Monit 2007;13:RA189-95.

14. Kanazawa H, Asai K, Hirata K, et al. Possible effects of vascular endothelial growth factor in the pathogenesis of chronic obstructive pulmonary disease. Am J Med 2003;114:354-8.

15. O'Donnell R, Breen D, Wilson S, et al. Inflammatory cells in the airways in COPD. Thorax 2006;61:448-54

16. Saetta M, Turato G, Maestrelli $P$, et al. Cellular and structural bases of chronic obstructive pulmonary disease. Am J Respir Crit Care Med 2001:163:1304-9.

17. Jones PW, Willits LR, Burge PS, et al. Inhaled steroids in obstructive lung disease in Europe study investigators. Disease severity and the effect of fluticasone propionate on chronic obstructive pulmonary disease exacerbations. Eur Respir J 2003;21:68-73.

18. Hattotuwa KL, Gizycki MJ, Ansari TW, et al. The effects of inhaled fluticasone on airway inflammation in chronic obstructive pulmonary disease: a double-blind, placebo-controlled biopsy study. Am J Respir Crit Care Med 2002;165:1592-6.

19. Gizycki MJ, Hattotuwa KL, Barnes NC, et al. Effects of fluticasone propionate on inflammatory cells in COPD: an ultrastructural examination of endobronchial biopsy tissue. Thorax 2002; 57:799-803.

20. Tomic R, Lassiter CC, Ritzenthaler JD, et al. Anti-tissue remodelling effects of corticosteroids. Fluticasone propionate inhibits fibronectin expression in fibroblasts. Chest 2005;127:257-65.
21. Pauwels RA, Buist AS, Calverley PM, et al. Global strategy for the diagnosis, management, and prevention of chronic obstructive pulmonary disease: NHLBI/WHO Global Initiative for Chronic Obstructive Lung Disease (GOLD) workshop summary. Am J Respir Crit Care Med 2001:163:1256-76.

22. Poli G, Acerbi D. Comparison of the bioavailability and systemic effects of beclometasone dipropionate suspension for nebulization and beclometasone dipropionate via a metered-dose inhaler after single-dose administration in healthy male volunteers. Respir Med 2003;97(Suppl B):S5-9

23. Chetta A, Foresi A, Del Donno M, et al. Airways remodeling is a distintive feature of asthma and is related to severity of disease. Chest 1997:111:852-7.

24. Britten KM, Howarth PH, Roche WR. Immunohistochemistry of resin sections, a comparison of resin embedding techniques for small mucosal biopsies. Biotech Histochem 1993;68:271-80.

25. Chetta A, Zanini A, Foresi A, et al. Vascular component of airway remodeling in asthma is reduced by high dose of fluticasone. Am J Respir Crit Care Med 2003; 167:751-7.

26. Kuwano K, Bosken $\mathrm{CH}$, Paré PD, et al. Small airways dimensions in asthma and chronic obstructive pulmonary disease. Am Rev Respir Dis 1993:148:1220-5.

27. Kranenburg AR, de Boer WI, van Krieken HJM, et al. Enhanced expression of fibroblast growth factors and receptor FGFR-1 during vascular remodeling in chronic obstructive pulmonary disease. Am J Respir Cell Mol Biol 2002:27:517-22.

28. Guddo F, Vignola AM, Saetta M, et al. Upregulation of basic fibroblast growth factor in smokers with chronic bronchitis. Eur Respir J 2006:27:957-63.

29. Takizawa H, Tanaka M, Takami K, et al. Increased expression of transforming growth factor-beta1 in small airway epithelium from tobacco smokers and patients with chronic obstructive pulmonary disease (COPD). Am J Respir Crit Care Med 2001;163:1476-83.

30. Bertolino $\mathbf{P}$, Deckers $M$, Lebrin $F$, et al. Transforming growth factor- $\beta$ signal transduction in angiogenesis and vascular disorders. Chest 2005;128:585-90.

31. Santibanez JF, Letamendia A, Perez-Barriocanal F, et al. Endoglin increases eNOS expression by modulating smad2 protein levels and smad2-dependent TGF- $\beta$ signaling. J Cell Physiol 2007;210:456-8.

32. Yang IA, Fong KM, Sim EH, et al. Inhaled corticosteroids for stable chronic obstructive pulmonary disease. Cochrane Database Syst Rev 2007;(2):CD002991.

33. Verhoeven GT, Hegmans JPJJ, Mulder PGH, et al. Effects of fluticasone propionate in COPD patients with bronchial hyperresponsiveness. Thorax 2002; 57:694-700.

34. Paredi $\mathbf{P}$, Ward S, Cramer D, et al. Normal bronchial blood flow in COPD is unaffected by inhaled corticosteroids and correlates with exhaled nitric oxide. Chest 2007; 131:1075-81

\section{Drug and Therapeutics Bulletin (DTB)}

\section{Your key source of unbiased, independent advice}

For over 45 years DTB has been an independent, indispensable part of evidence-based clinical practice. DTB offers healthcare professionals detailed assessment of, and practical advice on, individual medicines and other treatments, groups of treatment and the overall management of disease.

DTB is now also available online at http://dtb.bmj.com:

- browse or search all DTB content from the latest issue back to 1994

- email alerting, sophisticated searching, RSS feeds and full text links from cited references

- interactive services such as My Folders for quick access to articles that you have viewed previously and My Searches to save and re-use useful searches

- comment online on any DTB article

To subscribe, or for further information, please visit http://dtb.bmj.com 